\title{
Análise da implementação de mistura asfáltica com granulometria do tipo descontínua para redução de acidentes em pista molhada
}

\author{
Analysis of gap-graded asphalt mix as a pavement overlay to reduce \\ accidents in wet condition
}

\author{
Fernanda Santana Carvalho ${ }^{1}$, Cláudia A. Soares Machado², Liedi Légi Bariani Bernucci ${ }^{3}$ \\ ${ }^{1}$ Universidade de São Paulo, São Paulo - Brasil, carvalhofernanda@ufg.br \\ 2Universidade de São Paulo, São Paulo - Brasil, claudia.machado@usp.br \\ 3Universidade de São Paulo, São Paulo - Brasil, liedi@usp.br
}

\section{Recebido:}

15 de fevereiro de 2019

Aceito para publicação:

22 de julho de 2019

Publicado:

31 de agosto de 2020

Editor de área:

Jorge Barbosa Soares

\section{Palavras-chaves:}

Segurança viária.

Aderência pneu/pavimento.

Acidentes de tráfego.

Keywords:

Road safety.

Tire/pavement grip.

Traffic accidents.

DOI:10.14295/transportes.v28i3.1954

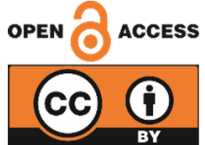

\begin{abstract}
RESUMO
Acidentes de trânsito são eventos complexos envolvendo múltiplas causas, geralmente conectados a falhas humanas relativas à interpretação do ambiente da via onde trafegam. Tais eventos causam perdas de vidas, além de prejuízos sociais e econômicos. Neste contexto, é essencial para a gestão de rodovias a execução de projetos que minimizem tais erros. Dentre os fatores mais estudados para reduzir acidentes encontra-se a infraestrutura viária, principalmente no que tange à geometria, à sinalização e às condições de superfície, com enfoque na aderência pneu/pavimento sob condições climáticas adversas. Este trabalho aborda a caracterização da superfície de pavimentos asfálticos em dois trechos experimentais que sofreram intervenção para aumento da drenagem superficial e consequente melhoria da oferta de atrito pelo emprego de mistura asfáltica do tipo gap-graded, que também passou por ensaios em laboratório para comprovação de sua efetividade. Por fim, confirmou-se empiricamente a eficiência deste revestimento asfáltico na redução do número de acidentes.
\end{abstract}

\section{ABSTRACT}

Traffic accidents are complex events involving multiple causes usually connected to human faults related to the interpretation of the environment of the road where they travel. Such events cause loss of life, as well as social and economic losses. In this context, it is essential for the management of highways to carry out projects that minimize such errors. Among the factors most studied to reduce accidents is the road infrastructure, especially with regard to geometry, road signs and surface conditions, with a focus on tire/pavement adhesion under adverse climatic conditions. This work deals with the characterization of the surface of asphaltic pavements in two experimental sections that have undergone intervention to increase surface drainage and consequent improvement of the friction supply by the use of a gap-graded asphalt mixture, which also underwent laboratory tests to prove effectiveness. The efficiency of this asphalt coating has been empirically confirmed in reducing the number of accidents.

\section{INTRODUÇÃO}

A American Association of State Highway and Transportation Officials (AASHTO, 2010) define acidente de trânsito como um conjunto de eventos resultantes em morte, ferimentos ou danos a propriedades, devido à colisão de pelo menos um veículo motorizado, podendo ainda envolver outros veículos motorizados ou não, pedestres ou objetos fixos. 
Segundo a Organização Mundial da Saúde (OMS, 2015) aproximadamente 1,25 milhões de pessoas morrem anualmente em acidentes de trânsito no mundo e o gasto estimado dos países em desenvolvimento representa 3\% de seu Produto Interno Bruto (PIB). 0 Instituto de Pesquisa Econômica Aplicada (IPEA, 2015) aponta que em 2014, devido aos 160 mil acidentes rodoviários no Brasil, gastou-se 40 bilhões de reais. Em contraponto, a Confederação Nacional dos Transportes (CNT, 2017) demonstrou que o investimento brasileiro em infraestrutura rodoviária no mesmo ano foi apenas $0,16 \%$ do PIB.

Segundo Noyce et al. (2005), um dos fatores causadores de acidentes mais estudado é a infraestrutura viária, tanto em relação às condições superficiais da pista, quanto à oferta de atrito em condições climáticas adversas. Caliendo et al. (2007) avaliaram o número de acidentes de dada rodovia, concluindo que os acidentes fatais estão correlacionados à presença de chuva, principalmente em curvas. Sugeriram, então, a troca do revestimento superficial do pavimento por uma camada que facilite a drenagem superficial, aumentando a aderência pneu/pavimento.

Geedipally (2005) analisou dados de número de acidentes antes e após a intervenção para melhoria do atrito de pavimentos urbanos, concluindo que houve redução de $50 \%$ no número de ocorrências após a troca de revestimento. Lyon et al. (2018) observaram também redução no número de acidentes em rodovias de pista dupla para situação de pista seca e molhada após emprego da técnica denominada Ultra-Thin Bonded Wearing Course (UTBWC). Tal técnica consiste na aplicação de uma fina camada de mistura asfáltica do tipo gap-graded sobre emulsão de ligante modificado (Corley-Lay e Mastin, 2007).

Dessa forma, o presente trabalho visa apresentar o efeito do aumento da aderência pneu/pavimento, por meio de uma intervenção na superfície de rolamento, no número de acidentes em pista molhada. Para tanto, foram construídos dois trechos experimentais nos quais se aplicou um revestimento asfáltico com mistura de granulometria descontínua, do tipo gap-graded, objetivando melhor drenagem superficial para aumento do atrito. Para fins de caracterização dos trechos em estudo foram aferidos periodicamente os valores de macrotextura e de atrito em campo. Além disso, foram ensaiadas em laboratório placas confeccionadas com material advindo do momento da execução dos mesmos. Por fim, analisaram-se os dados de acidentes ocorridos para apresentação da redução desses eventos.

\section{ACIDENTES E SUAS CAUSAS}

AASHTO (2010) considera acidentes de trânsito como eventos únicos e aleatórios resultantes de um conjunto de fatores. Noyce et al. (2005) acrescentam que esses eventos decorrem da falha do motorista em lidar com o ambiente em que se encontra. A AASHTO (2010) explana que suas limitações físicas, perceptivas e cognitivas são as maiores fontes de erro. Uma vez que não é possível eliminar essas limitações, medidas devem ser tomadas para que o sistema viário as minimize.

Portanto, deve ser entendida a interação motorista/via para criação de projetos seguros. A primeira questão a ser analisada diz respeito à relação geometria da via e a velocidade, devendo-se garantir um traçado com mudanças suaves, sem alterações bruscas de velocidade (AASHTO, 2010).

Outro quesito importante diz respeito à sinalização e à visibilidade da pista. Para a AASHTO (2010) 90\% das informações utilizadas pelo condutor são adquiridas visualmente. Dessa forma, a sinalização horizontal, que delimita a via, tem importante função no seu funcionamento (Carlson et al., 2009). Por sua vez, a sinalização vertical, segundo CROW (2009), tem profunda 
intimidade com o projeto geométrico da via e deve ser uniforme, consistente, legível e de fácil entendimento.

Por fim, ressalta-se a questão da manutenção do veículo na pista e execução de manobras, resultados do atrito pneu/pavimento (Hall et al., 2009). A força que resiste ao movimento do pneu sobre a superfície do pavimento, gerando resistência à derrapagem é denominada de atrito (Noyce et al., 2005). Dessa forma, se a superfície do pavimento é mantida a um bom nível de macrotextura, garante-se uma boa resistência à derrapagem (Henry, 2000).

\subsection{Aderência pneu/pavimento}

A superfície de um pavimento asfáltico não é plana e seus desvios são classificados como sua textura (Hall et al., 2009). Considerando-se que esses desvios se aproximem de curvas senoidais, são classificados quatro níveis de textura: irregularidades. megatextura, macrotextura e microtexura (Flintsch et al., 2012). Dado que a superfície é o meio de contato responsável pela manutenção do atrito pneu/pavimento, os dois últimos níveis de textura são correlacionados a essa característica.

A macrotextura, com comprimentos de ondas de $0,5 \mathrm{~mm}$ a $50 \mathrm{~mm}$, se relaciona com a graduação, tamanho máximo, espaçamento e formato dos agregados. Já a microtextura é dada pelos comprimentos de onda de $1 \mu \mathrm{m}$ a 0,5 $\mathrm{mm}$, sendo influenciada pela rugosidade superficial dos mesmos (Hall et al., 2009). Para Henry (2000) se esses dois níveis são satisfatórios na textura superficial do pavimento, garante-se uma boa resistência à derrapagem. Assim sendo, a otimização na escolha de macro e microtextura é o que garante o atrito determinado em projeto (Hall et al., 2009).

Quanto ao projeto de misturas asfálticas, estuda-se o efeito da granulometria na melhoria da aderência pneu/pavimento. Isso se dá porque misturas com granulometria contínua, ou seja, bem graduadas, tendem a apresentar texturas superficiais mais fechadas e com drenagem superficial, por vezes, deficiente, enquanto que misturas projetadas com maiores diâmetros máximos de agregados e maior volume dos mesmos, geralmente, apresentam uma macrotextura mais adequada (Aps, 2006). Dessa forma, explica-se a utilização de misturas denominadas gapgraded. Segundo Bernucci et al. (2008) tais misturas tendem a apresentar macrotextura classificada como aberta ou rugosa por se enquadrarem na classificação de granulometria descontínua, entretanto, sem teor de vazios elevado.

A drenagem superficial da pista é importante para a manutenção da aderência pneu/pavimento e a condição de pista molhada é a mais crítica quanto à ocorrência de acidentes. Nesse sentido, Flintsch et al. (2012) determinam que enquanto a macrotextura é responsável por dispersar a película de água depositada sobre a pista durante a precipitação, a microtextura deve garantir o contato com o pneu ao atravessar finas camadas de água. Dessa forma, a microtextura é importante a baixas velocidades e a macrotextura é fundamental para veículos a altas velocidades trafegando em pista molhada.

\subsection{Medições de atrito e textura}

A caracterização da macrotextura e do atrito oferecido pelo pavimento são fundamentais para identificação de trechos a serem restaurados.

Wambold et al. (1995) determinam três tipos de métodos para obtenção dos valores de macrotextura: volumétricos, drenômetros e perfilômetros. De fácil execução e classificado como 
volumétrico o ensaio da Mancha de Areia ainda é o mais empregado (Gao et al., 2019). Este consiste no espalhamento de $25.000 \mathrm{~mm}^{3}$ de esferas de vidro, com granulometria especificada pela ASTM E965-15 (2018), num formato circular e com o auxílio de um pistão com base de borracha. Após aferir quatro vezes o diâmetro do círculo formado deve-se calcular sua área. Uma vez que são conhecidas a área e o volume de material define-se a altura do mesmo sobre o pavimento.

O parâmetro de altura obtido é comumente denominado de Mean Texture Depth (MTD) e segundo o Departamento Nacional de Infraestrutura de Transportes (DNIT, 2006) deve se encontrar entre os valores de $0,6 \mathrm{~mm}$ a 1,2 mm. 0 mesmo órgão estabelece classificações para os níveis de macrotextura, conforme Tabela 1(a).

Outra forma de caracterização da macrotextura se dá por meio do parâmetro de Mean Profile Depth (MPD) (ASTM E1845-15, 2018) e que pode ser obtido pelo equipamento de perfilômetro laser. Este atua emitindo um feixe de raios laser sobre o pavimento e mensurando a distância por captação da onda de retorno. Tal equipamento não requer contato com a superfície a ser aferida e está em geral acoplado a um veículo realizando medições a uma velocidade constante.

Já para os métodos de medição de atrito, há quatro classificações: estáticos, de roda oblíqua, de roda bloqueada e de roda parcialmente bloqueada (Aps, 2006). Dentre os estáticos se encontra o Pêndulo Britânico que afere valores de atrito sendo influenciado majoritariamente pela microtextura (ASTM E303-93, 2018).

Esse ensaio é realizado sobre um pavimento aspergido com água onde deve ser solto o pêndulo. 0 mesmo toca a superfície através de uma sapata de borracha e, por meio de tal movimento, é modificada a posição do ponteiro de medição. Lê-se, então, na escala o valor do British Pendulum Number (BPN) também denominado valor de resistência à derrapagem (VRD). A Tabela 1(b) mostra os valores de classificação definidos pelo DNIT (2006) que também estabelece que os valores de VRD devem se encontrar acima de 55.

\begin{tabular}{|c|c|}
\hline Classe de macrotextura & Altura média de mancha de areia \\
\hline Muito fina ou muito fechada & $\mathrm{MTD} \leq 0,20$ \\
\hline Fina ou fechada & $0,20<\mathrm{MTD} \leq 0,40$ \\
\hline Média & $0,40<\mathrm{MTD} \leq 0,80$ \\
\hline Grosseira ou aberta & $0,80<\mathrm{MTD} \leq 1,20$ \\
\hline Muito grosseira ou muito aberta & MTD $>1,20$ \\
\hline
\end{tabular}

(a)

\begin{tabular}{ll}
\hline Classe de macrotextura & Valor de resistência à derrapagem \\
\hline Perigosa & VRD $<25$ \\
Muito lisa & $25 \leq \mathrm{VRD} \leq 31$ \\
Lisa & $32 \leq \mathrm{VRD} \leq 39$ \\
Insuficientemente rugosa & $40 \leq \mathrm{VRD} \leq 46$ \\
Medianamente rugosa & $47 \leq \mathrm{VRD} \leq 54$ \\
Rugosa & $55 \leq \mathrm{VRD} \leq 75$ \\
Muito rugosa & $\mathrm{VRD}>75$ \\
\hline
\end{tabular}

(b) 
Outro equipamento empregado para medições de atrito pneu/pavimento é o GripTester, um trailer que apresenta três rodas sendo a do centro parcialmente bloqueada, de forma que se desloque mais lentamente que as outras duas. Assim, cria-se uma força de frenagem, sendo a mesma medida no eixo da roda e denominada Grip Number (GN) (Chou et al., 2017). Segundo Freitas e Pereira (2008) o GripTester deve percorrer o pavimento a uma velocidade constante próxima a $60 \mathrm{~km} / \mathrm{h}$, aspergindo-o com água e criando uma película de 1,0 mm.

Como visto, numerosas combinações de medições de atrito e textura podem ser realizadas. Para que essas medições se tornassem comparáveis, a Permanent International Association of Road Congress (PIARC) propôs o International Friction Index (IFI) através de Wambold et al. (1995) e seu procedimento de cálculo é encontrado na ASTM E1960-07 (2015). Para aplicação desse índice determinaram-se equações utilizadas para a harmonização entre diferentes equipamentos, bem como, as constantes específicas para cada um. Para classificação dos valores obtidos de IFI, Aps (2006) propôs, baseada em resultados experimentais executados no Brasil, intervalos conforme Tabela 2.

Tabela 2 - Classificação segundo o IFI (Aps, 2006)

\begin{tabular}{lll}
\hline Classificação & Faixa de IFI & \\
\hline Péssimo & $\leq 0,05$ & \\
Muito Ruim & 0,06 & 0,08 \\
Ruim & 0,09 & 0,11 \\
Regular & 0,12 & 0,14 \\
Bom & 0,15 & 0,21 \\
Muito Bom & 0,22 & 0,35 \\
Ótimo & $>0,35$ & \\
\hline
\end{tabular}

Por fim, apresentam-se as técnicas de caracterização de textura por imagem, como a estéreo fotometria que consiste na obtenção sequencial de fotografias de uma superfície, de forma que, mantendo-se a mesma posição da câmera, varie-se a angulação da luz incidente (WOODHAM, 1980). Esse é o princípio de funcionamento da Pavement Texture Analyzer (PTA), equipamento desenvolvido no Laboratório de Tecnologia de Pavimentação (LTP) da Escola Politécnica da USP (EPUSP) (registro número BR102013013198-9). Pelo seu emprego obtêm-se parâmetros estatísticos relativos à distribuição dos agregados na superfície dos corpos de prova. Assumindo-se que essa distribuição seja normal, tais parâmetros são assimetria e curtose (Vieira, 2014; Kuchiishi et al., 2014).
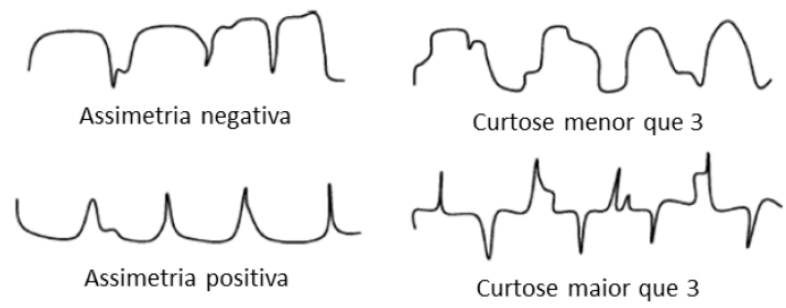

Figura 1: Superfície do pavimento em função da assimetria e curtose (Kuchiishi et al., 2014)

Para Vieira e Sandberg (2018), uma assimetria com valores positivos indica textura positiva, predominância de picos, enquanto que o oposto é válido para textura negativa, predominância de vales. Os autores definem que uma textura negativa representa uma melhor distribuição de pressão no contato pneu/pavimento e, portanto, um melhor comportamento quanto à 
resistência à derrapagem. Por outro lado, a curtose se relaciona ao quão pronunciados são os picos e vales. Uma curtose com valores maiores que três indica que os mesmos são afinados e menor que três que estes são achatados (Kuchiishi et al., 2014). A Figura 1 resume os parâmetros obtidos pelo ensaio.

\section{METODOLOGIA EMPREGADA}

A fim de caracterizar a intervenção realizada no pavimento e suas consequências, neste trabalho são apresentados ensaios de campo e de laboratório, além do acompanhamento da frequência dos acidentes nesses trechos através de dados disponibilizados pela Concessionária Autopista Régis Bittencourt, filiada ao grupo ARTERIS.

\subsection{Trechos experimentais}

A Rodovia Régis Bittencourt (BR-116), concessionada pela Autopista Régis Bittencourt desde 2008, liga Curitiba a São Paulo num segmento de aproximadamente 400 quilômetros. Tal rodovia apresenta intervalos em serra marcados por traçado com aclives e declives, bem como, curvas acentuadas criando um ambiente propício para problemas de visibilidade e acréscimo de acidentes em pista molhada. Dessa forma, vêm sendo estudadas soluções para redução desses eventos.

Nesse sentido, utilizando dados de volume de tráfego e acidentes entre os anos de 2008 a 2016, foram determinados trechos críticos em relação ao número de acidentes em pista molhada dentre os quais dois, localizados no sentido norte da rodovia, foram selecionados como trechos experimentais. Houve a troca de revestimento da pista nesses dois locais buscando uma melhor drenagem superficial e maior oferta de atrito pneu/pavimento.

Para a intervenção, foi projetada pela Autopista Régis Bittencourt uma mistura do tipo gapgraded, com diâmetro máximo nominal de 9,5 mm e agregado de origem granítica, apresentando um teor ótimo de ligante de 5,5\% e um volume de vazios de projeto igual 5\%. 0 ligante asfáltico empregado apresentava modificação por polímero elastomérico sendo classificado por E 60/85. Os parâmetros de dosagem da mistura asfáltica são apresentados na Tabela 3 e sua distribuição granulométrica na Figura 2.

Tabela 3 - Parâmetros de dosagem (Autopista Régis Bittencourt, 2016)

\begin{tabular}{ll}
\hline Parâmetro & Valores \\
\hline Teor de Ligante (\%) & 5,5 \\
Massa Específica Aparente $\left(\mathrm{g} / \mathrm{cm}^{3}\right)$ & 2,397 \\
Massa Específica Máxima $\left(\mathrm{g} / \mathrm{cm}^{3}\right)$ & 2,523 \\
Volume de vazios $(\%)$ & 5 \\
Vazios do Agregado Mineral (\%) & 16,1 \\
Vazios Cheios de Asfalto (\%) & 68,9 \\
Resistência à Tração Indireta a 25 oC (MPa) & 2,0 \\
Porcentagem de grãos com Relação > 1:3 & 14 \\
Desgaste Los Angeles (\%) & 12 \\
\hline
\end{tabular}

Uma vez projetada a mistura, a mesma foi executada no Trecho Experimental $1(\mathrm{~km} 518$ a km 517+530 - liberado ao tráfego em 26/06/2016) e no Trecho Experimental 2 (km 545+370 a km 544+720 - liberado ao tráfego em 12/07/2016). Por se tratar do sentido norte da rodovia, direção Curitiba - São Paulo, os quilômetros são apresentados de forma decrescente. 
Ressalta-se que no momento da aplicação do novo revestimento foram coletadas amostras do material aplicado no Trecho Experimental 2 para realização dos ensaios em laboratório.

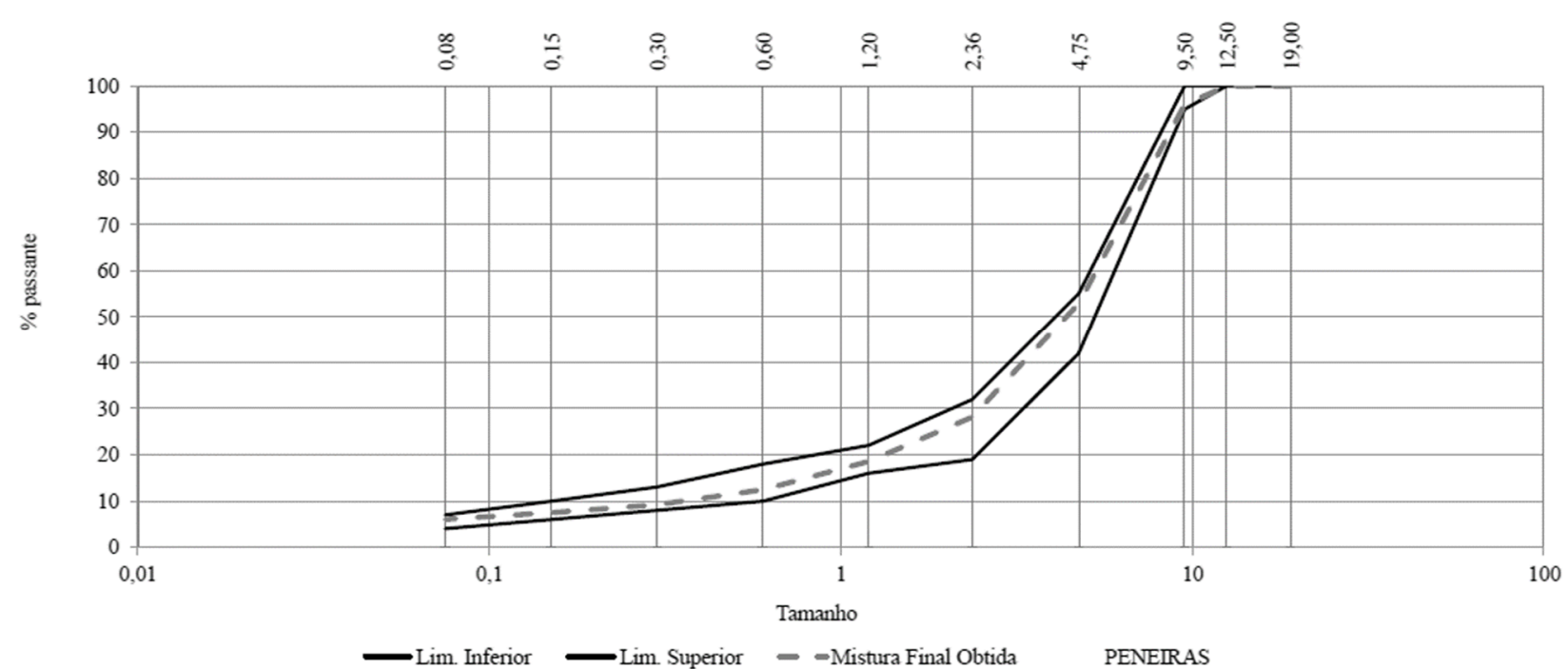

Figura 2. Distribuição granulométrica da mistura empregada nos trechos experimentais (Autopista Régis Bittencourt, 2016)

\subsection{Ensaios de campo}

Para caracterização dos trechos experimentais, quatro medições foram feitas na rodovia: a primeira em 2015 (medição 1), período anterior à intervenção; a segunda em dezembro de 2016 (medição 2); a terceira em dezembro de 2017 (medição 3); e, por fim, uma no mês de junho de 2018 (medição 4). Entretanto, no momento da realização da primeira medição não se sabia ao certo a futura localização dos trechos experimentais, de forma que, não foram abrangidos os quilômetros que posteriormente sofreram a intervenção. Sendo assim, tomou-se por hipótese que o tipo de pavimento era similar em trechos contíguos dado que se sabe que na região a mistura aplicada era do tipo densa e que não haviam ocorrido outras intervenções em nenhum trecho próximo, expandindo-se a média dos resultados da medição 01 como representativos do estado anterior do pavimento antes da intervenção.

Em cada uma das medições foram realizados ensaios de macrotextura pelo equipamento de perfilômetro laser e utilizando o parâmetro de MPD e de atrito pelo trailer denominado GripTester, utilizando o parâmetro GN. A escolha dos equipamentos levou em conta a manutenção da operação da rodovia, sem interrupção do fluxo de veículos. Além disso, ambos ensaios foram realizados a cada dez metros, segundo a necessidade de espaçamento do GripTester, primeiro sobre a trilha de roda da faixa 1 e depois da faixa 2 de cada trecho. Esclarecendo que, para os padrões brasileiros, as faixas são contadas da esquerda para a direita de modo que na faixa 1 , geralmente, trafegam os veículos leves, enquanto que nas faixas mais à direita trafegam veículos pesados.

\subsection{Ensaios de laboratório}

Com a realização dos ensaios de laboratório objetivou-se a determinação dos valores de macrotextura e atrito do pavimento, pelo emprego dos ensaios de Mancha de Areia e Pêndulo Britânico, respectivamente. Destaca-se que o ensaio de Mancha de Areia foi realizado em todas as etapas pelo mesmo operador, evitando maior variabilidade nos resultados dos ensaios. 
O ensaio de Pêndulo Britânico foi realizado nos mesmos locais das placas aferidos pelo de Mancha de Areia. Adicionalmente, foi utilizada a PTA a fim de determinar uma natureza de textura positiva ou negativa para a mistura asfáltica.

Tais ensaios foram realizados em quatro etapas intercaladas com o uso do simulador de tráfego do tipo Laboratoire Central des Ponts Chaussess (LCPC) do LTP-EPUSP. A simulação consiste na aplicação de cargas através de pneus, que se deslocam numa frequência de $1 \mathrm{~Hz}$, sobre duas placas localizadas à direita e à esquerda do simulador. Os ciclos de passagem de carga são contados de forma acumulada e vão até 30.000. Sendo assim, as placas foram ensaiadas antes da passagem no simulador, aos 3.000 ciclos, aos 10.000 ciclos e aos 30.000 ciclos, conforme Figura 3.

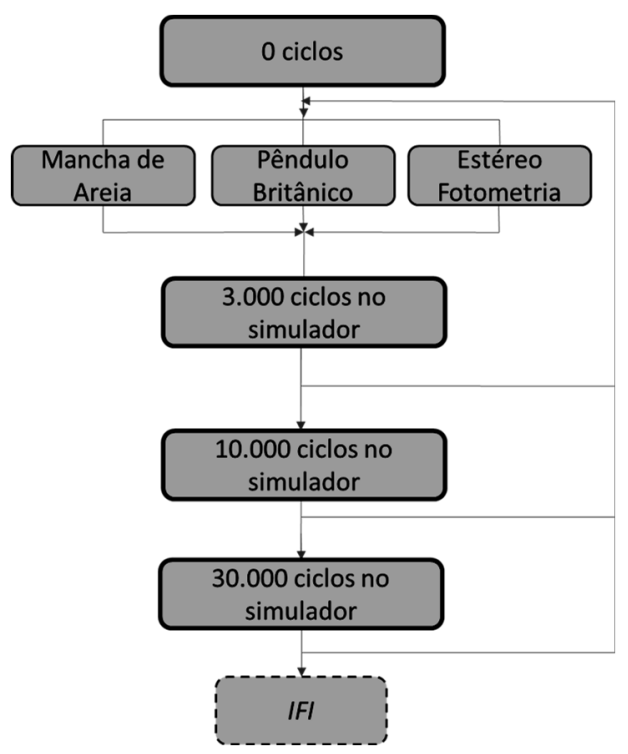

Figura 3. Etapas de realização dos ensaios em laboratório

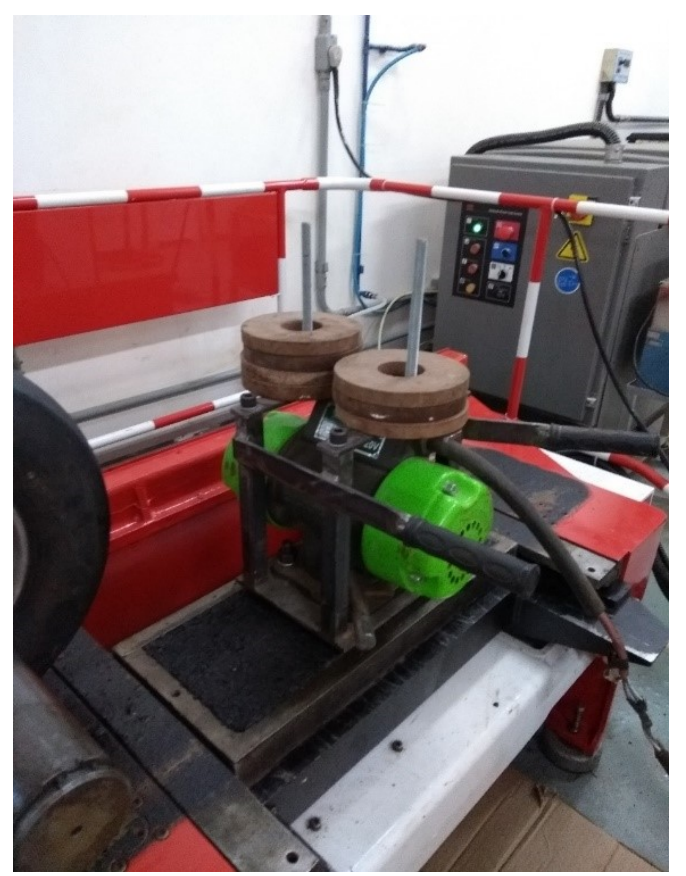

Figura 4. Equipamentos utilizados na compactação: Mesa compactadora do tipo LCPC e equipamento de vibração disposto sobre a placa 
Para tanto, foram confeccionadas duas placas com comprimento $c=18 \mathrm{~cm}$, largura $l=50 \mathrm{~cm}$ e espessura $t=5 \mathrm{~cm}$ com o material advindo da execução do Trecho Experimental 2. Para amoldamento das placas o material foi reaquecido a aproximadamente $145^{\circ} \mathrm{C}$ e compactado. Quanto ao método de compactação, foram empregadas duas técnicas de forma seguida: (1) compactação por rolo pneu na mesa compactadora do tipo LCPC do LTP-EPUSP e (2) compactação por vibração por equipamento adaptado no mesmo laboratório, ambas apresentadas na Figura 4. Esse procedimento foi adotado porque em pesquisas anteriores, Pereira et al. (2012) constataram que a utilização do simulador de tráfego em placas que passaram apenas pela mesa compactadora ocasionava o deslocamento dos agregados gerando ganhos falsos de textura, sugerindo a incorporação da vibração na execução das mesmas.

Por fim, os resultados foram classificados conforme Tabela 1, e calculados e classificados os valores de IFI segundo a Tabela 2.

\section{RESULTADOS}

Nas seções 4.1 a 4.3 são apresentados os resultados encontrados em campo, em laboratório e o monitoramento do número de acidentes.

\subsection{Ensaios de campo}

Na Figura 5 são apresentadas as médias dos resultados das medições do perfilômetro laser e do GripTester para o Trecho Experimental 1, em suas faixas 1 e 2.

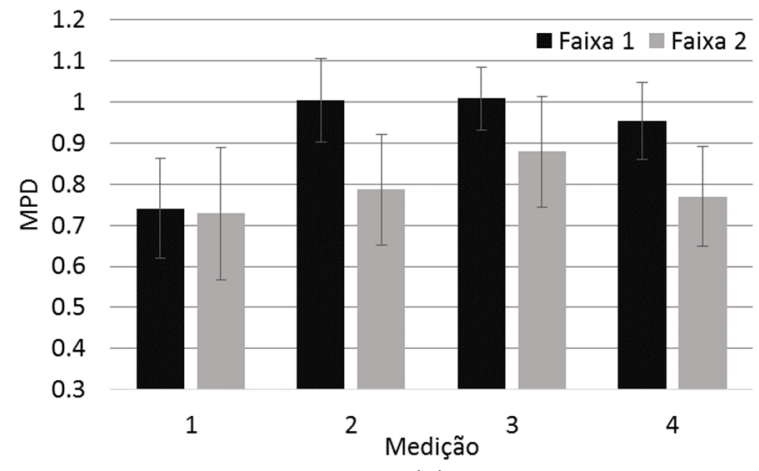

(a)

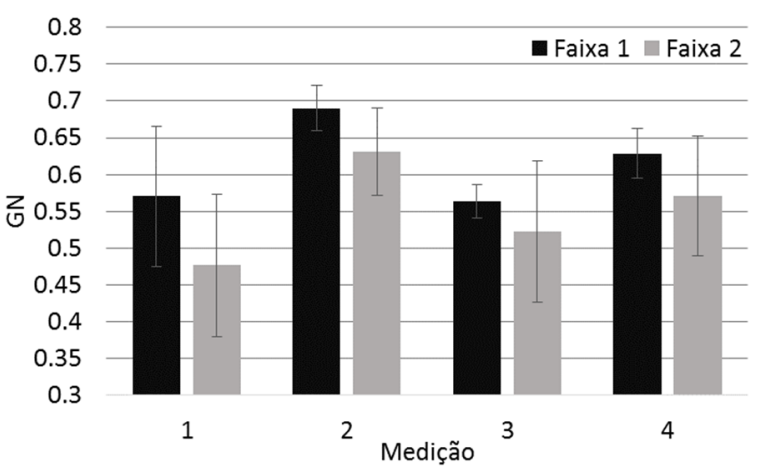

(b)

Figura 5. Resultados para o Trecho Experimental 1 das medições de (a) macrotextura e (b) atrito - Medição 1 antes e medições 2, 3 e 4 após a intervenção no revestimento asfáltico

Dado que a medição 1 representa o estado geral da rodovia anteriormente à intervenção, vê-se que a medição 2 apresenta médias maiores tanto para os valores de MPD quanto para os de GN, ou seja, após aproximadamente seis meses da instalação da intervenção os valores aferidos se encontravam melhores que o estado geral da rodovia antes da intervenção.

Outra observação é que a faixa 2 do Trecho Experimental 1 apresenta resultados inferiores aos da faixa 1. Isso se dá porque as duas foram executadas separadamente, não apresentando a mesma textura. Além disso, o tráfego de veículos comerciais pesados presente na faixa 2 torna seu desgaste superficial mais acelerado, causando polimento superficial e perda de atrito.

De forma geral, apesar das variações nas médias de MPD, as mesmas se mantêm sempre acima da média anterior à intervenção. 0 mesmo não acontece para os valores de GN, visto que, a medição 3 atinge valores próximos à medição 1. Uma das explicações aplicáveis é a variação 
dos valores de atrito devido ao período chuvoso do ano. Medições realizadas próximas a dias com precipitação tendem a apresentar melhores resultados devido à retirada dos finos de poeira presos à superfície da pista. Além disso, as medições são suscetíveis a variações nos equipamentos ou na forma de operá-los.

Na Figura 6 são apresentadas as médias dos resultados para os ensaios de perfilômetro a laser para e GripTester para as faixas 1 e 2 do Trecho Experimental 2.

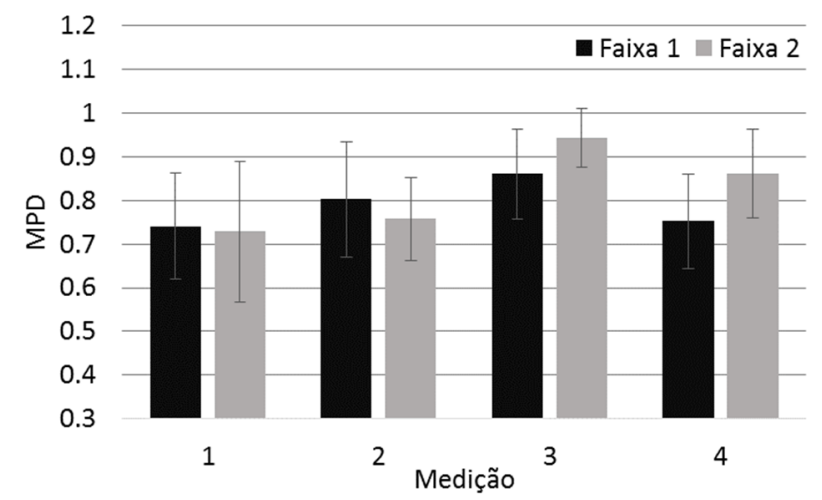

(a)

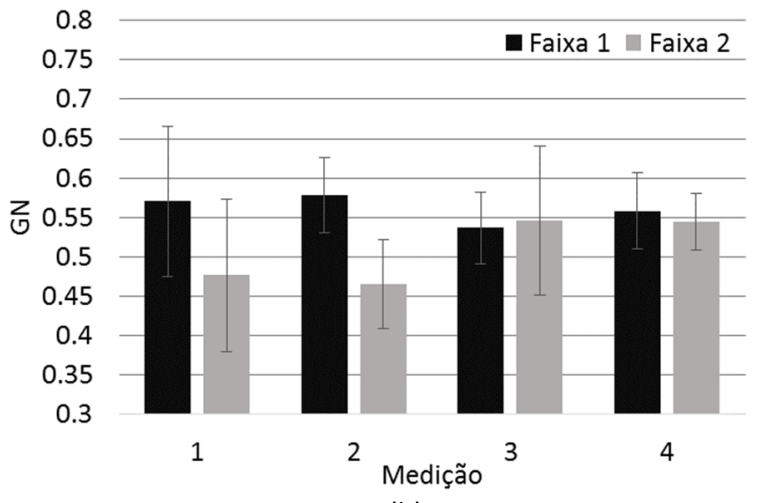

(b)

Figura 6. Resultados para o Trecho Experimental 2 das medições de (a) Textura e (b) Atrito - Medição 1 antes e medições 2, 3 e 4 após a intervenção no revestimento asfáltico

Quanto aos valores de MPD, pela Figura 6(a) observa-se que os valores de média de textura nesse trecho apresentaram mais variações que no Trecho Experimental 1, sendo que, a última medição para a faixa 1 tem valores de média próximos à da primeira medição. Acredita-se que isso se deva ao desgaste já ocorrido na superfície associado às variações de teor de ligante/granulometria da intervenção asfáltica neste Trecho 2, podendo ser constatada a macrotextura já mais fechada que no Trecho Experimental 1.

Quanto ao GN, para a faixa 1, as médias aferidas para as medições 2, 3 e 4 se apresentaram próximas à média da medição 1. Para a faixa 2 do Trecho Experimental 2, percebe-se pelos valores de MPD e de GN que a mesma apresenta melhores resultados nas medições 3 e 4 . Esse fato está ligado a um escorregamento de massa que ocorreu nessa faixa logo após a liberação do trecho devido a problemas na execução da pintura de ligação. Por conta disso, o pavimento da faixa 2 precisou ser refeito, e a pista foi liberada ao tráfego em abril de 2017, de forma que aos ensaios realizados após essa data apresentam melhores resultados.

São apresentados os valores de IFI calculados para as Faixas 1 e 2 dos Trechos Experimentais 1 e 2 na Figura 7. Nos gráficos se vê demarcado o valor de 0,35 representando o limiar entre as classificações Muito Bom e Ótimo, ou seja, os valores de IFI acima desta linha são considerados ótimos.

Nas Figuras 7(a) e (b) são apresentados os valores de IFI calculados para as faixas 1 e 2 do Trecho Experimental 1. O IFI calculado para as três medições na faixa 1 do Trecho Experimental 1 se classificou majoritariamente como Ótimo. A única exceção se configura no segmento km 517+950 a 517+930, classificados como Muito Bons. Já para a faixa 2, uma discrepância ocorre principalmente na medição 3, onde são aferidos trechos classificados como bons e muito bons. Esse pico negativo nas medições representa alguma patologia no revestimento asfáltico posteriormente corrigida pela concessionária pela inserção de uma mistura asfáltica densa tipo 
concreto asfáltico. Entretanto, os outros quilômetros ensaiados se classificaram majoritariamente como Ótimos.

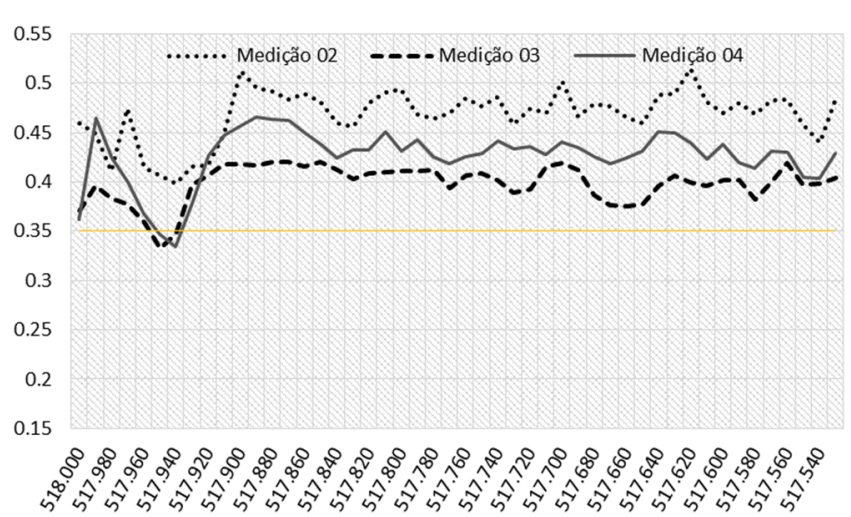

(a)

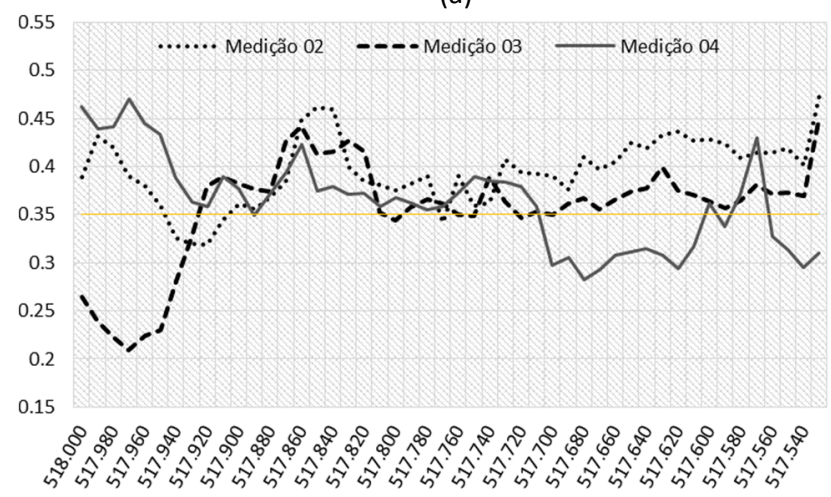

(b)

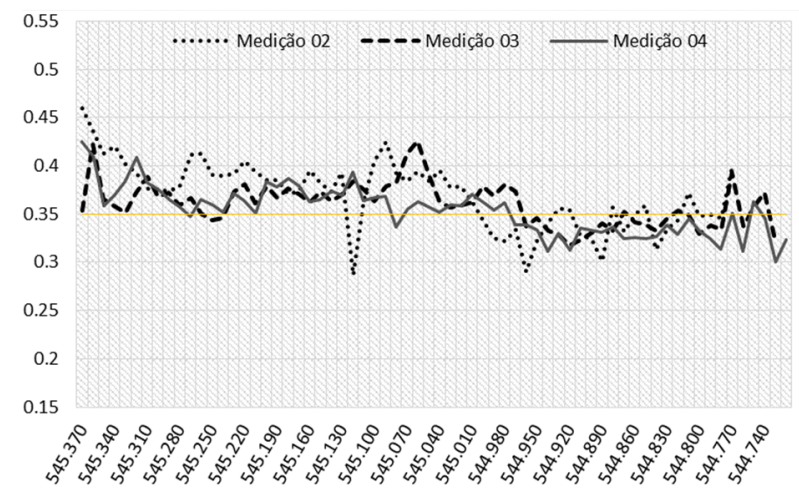

(c)

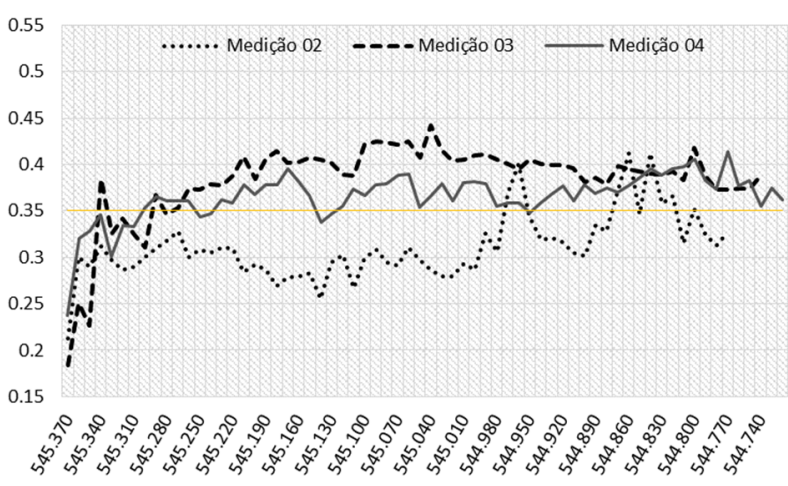

(d)

Figura 7. Resultados de IFI para (a) Trecho Experimental 1 faixa 1, (b) Trecho Experimental 1 faixa 2 (c) Trecho Experimental 2 faixa 1, (d) Trecho Experimental 2 faixa 2

Nas Figuras 7(c) e (d) são apresentados os valores de IFI calculados para as faixas 1 e 2 do Trecho Experimental 2. O IFI calculado para o Trecho Experimental 2 faixa 1 é predominantemente Ótimo até o km 545+040, a partir do qual sobrepôs-se a classificação Muito Bom. Já na faixa 2 do Trecho Experimental 2 fica nítida a discrepância de valores na medição 2, ou seja, a faixa que sofreu escorregamento e foi refeita. Essa medição se classifica em grande parte como muito boa, enquanto que as medições 3 e 4 se classificam em grande parte como Ótimas à exceção dos primeiros 90 metros.

Observa-se também que na maioria dos gráficos apresentados nesta seção, que os valores de IFI demonstram uma mesma tendência em todas as medições para a faixa e trecho em que estão, com predominância de medições classificadas como Ótimas.

\subsection{Ensaios de laboratório}

Para os ensaios de laboratório, os valores de MTD e BPN encontrados confirmaram bons padrões de textura apesar de algumas medições demonstrarem um resultado de Mancha de Areia superior ao recomendado pelo DNIT (2006) de 1,2 mm. Tal fato reforça a característica da mistura do tipo gap-graded de apresentar bons níveis de macrotextura. Pereira et. al. (2012) afirmam que é usual que os valores de macrotextura de laboratório sejam mais abertos que as encontradas em campo, ou seja, os ensaios de laboratório evidenciam as características principais da mistura. Além disso, todos os IFI calculados foram classificados como Ótimos. 
Quanto aos resultados de ensaio de estéreo fotometria, houve a predominância de uma textura negativa, em conformidade com os ensaios apresentados por Vieira (2014), que também ensaiou uma mistura do tipo gap-graded. Para Vieira e Sandberg (2018) esse resultado indica um bom comportamento da mistura quanto à resistência à derrapagem, porque representa uma melhor distribuição de pressão no contato pneu/pavimento. Entretanto, os valores de curtose apresentados nos ensaios não seguiram os mesmos padrões que os valores obtidos pelo ensaio de Pêndulo Britânico. Os resultados mostram que o passar dos pneus faz com que os picos dos agregados tendam a ficar cada vez mais abatidos, achatados e o ligante faz os vales "fecharem", mostrando pequena exsudação ou afundamento na placa pela simulação de tráfego. Estes estudos devem ser aprimorados e são os primeiros que procuram explorar estes dados.

$\mathrm{Na}$ Tabela 4 são apresentados os resultados dos ensaios de laboratório para as placas 01 e 02.

Tabela 4 - Resultados dos ensaios de laboratório

\begin{tabular}{ccccccccccc}
\hline Placa & Ciclos & $\begin{array}{c}\text { MTD } \\
(\mathrm{mm})\end{array}$ & Classif. & BPN & Classif. & Assimetria & Curtose & Resultado & IFI & Classif. \\
\hline \multirow{4}{*}{1} & 0 & 1,26 & Muito aberta & 79 & Muito rugosa & $-0,0055$ & 2,1571 & Negativa achatada & 0,59 & Ótimo \\
& 3000 & 1,31 & Muito aberta & 75 & Rugosa & $-0,0068$ & 2,5379 & Negativa achatada & 0,56 & Ótimo \\
& 10000 & 1,50 & Muito aberta & 71 & Rugosa & 0,0083 & 2,4349 & Positiva achatada & 0,56 & Ótimo \\
& 30000 & 1,26 & Muito aberta & 75 & Rugosa & $-0,0033$ & 1,9297 & Negativa achatada & 0,56 & Ótimo \\
\hline \multirow{4}{*}{2} & 0 & 0,99 & Aberta & 75 & Rugosa & $-0,0031$ & 1,7281 & Negativa achatada & 0,50 & Ótimo \\
& 3000 & 1,14 & Aberta & 76 & Muito rugosa & $-0,0029$ & 2,028 & Negativa achatada & 0,54 & Ótimo \\
& 10000 & 1,01 & Aberta & 70 & Rugosa & 0,0033 & 2,3391 & Positiva achatada & 0,47 & Ótimo \\
& 30000 & 1,37 & Muito aberta & 76 & Muito rugosa & $-0,0053$ & 2,0506 & Negativa achatada & 0,58 & Ótimo \\
\hline
\end{tabular}

Outra questão importante são os resultados apresentados aos 10.000 ciclos, para ambas as placas, onde a textura se apresentou como positiva e pouco pronunciada (achatada). Acreditase que os 10.000 ciclos representam alteração na textura superficial, principalmente para Placa 02, na qual se percebe que esse ponto é um pico máximo no valor MTD e mínimo no de BPN. A movimentação dos agregados pela passagem do pneu do simulador e descolamento da capa de ligante dos mesmos são as hipóteses mais presumíveis para essa alteração.

\subsection{Monitoramento do número de acidentes}

Os gráficos com o acompanhamento do número de acidentes são apresentados na Figura 8(a) para o Trecho Experimental 1 e (b) para o Trecho Experimental 2.

Em ambos os gráficos o número de acidentes em pista molhada excede o em pista seca, indicando acúmulo de água na pista e, consequentemente, textura do pavimento ou geometria da pista inadequada. Comparando-se os dois Trechos Experimentais percebe-se que o 1 tem histórico de uma média de acidentes mais elevada que o Trecho Experimental 2.

Ao analisar a Figura 8(a) e (b) é nítido o decréscimo do número de acidentes logo após as intervenções, sinalizadas pelas linhas tracejadas. Para o Trecho Experimental 1 a redução de acidentes atinge maiores proporções, com a manutenção do número de acidentes igual a zero por alguns meses. Entretanto, esses eventos voltaram a acontecer com maior frequência no segundo semestre de 2017, superando o período antes da troca de revestimento. Já no Trecho Experimental 2 a intervenção também zera os acidentes, e diferentemente do outro Trecho Experimental, eles retomam um nível de ocorrência constante ainda no ano de 2016, 
sem se igualar ou superar o período anterior à intervenção. Essa diferença entre trechos pode ser explicada, em partes, pelo fato da faixa 2 do Trecho Experimental 2 ter sido refeita, conforme explicado anteriormente. Essa nova intervenção garantiu melhores níveis de textura para essa faixa ocasionando a não elevação do número de acidentes.

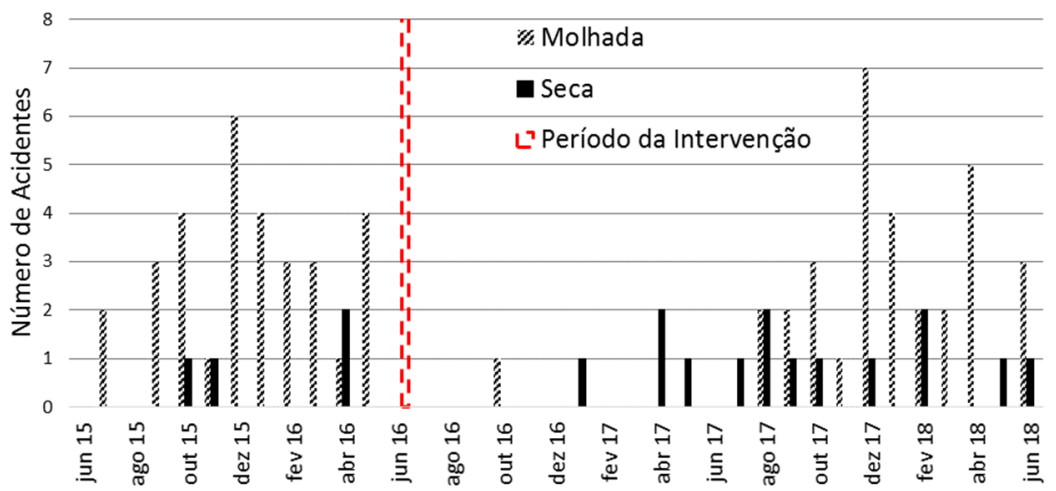

(a)

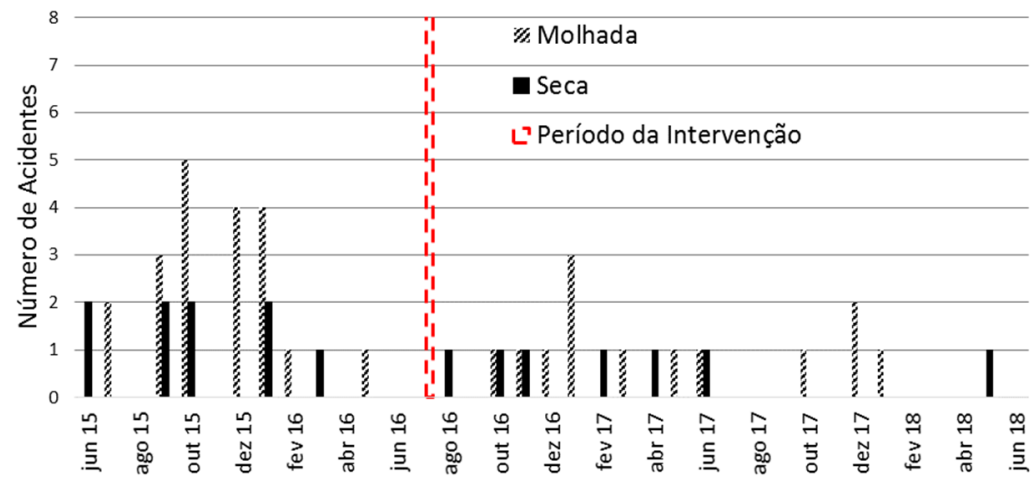

(b)

Figura 8. Número de acidentes no (a) Trecho Experimental 1 e (b) no Trecho Experimental 2

Ressalta-se que nesse estudo considerou-se que toda a variação do número de acidentes seja decorrente da troca do revestimento asfáltico, dado que nos períodos utilizados para a análise não houve outra intervenção na rodovia em estudo, nem variações significativas no fluxo de veículos. Entretanto, para análises mais aprofundadas da efetividade do efeito da intervenção devem ser feitos estudos seguindo a metodologia Antes/Depois apresentada por Hauer (1997).

\section{CONCLUSÕES}

0 presente trabalho apresentou a caracterização de dois Trechos Experimentais nos quais houve intervenção no revestimento asfáltico e incorporação de uma camada de mistura do tipo gap-graded. Foram apresentados os valores aferidos de macrotextura (MPD) e de atrito (GN) com os quais foram calculados os valores de IFI. Os resultados foram satisfatórios, sendo predominantemente classificados como Ótimos e garantindo que a textura superficial da mistura com granulometria do tipo descontínua oferece o atrito esperado para melhoria da aderência pneu/pavimento.

A fim de confirmar em laboratório as características da mistura asfáltica empregada em campo foram ensaiadas placas confeccionadas com mistura asfáltica do Trecho Experimental 2. Tanto a macrotextura, quanto a microtextura, apresentaram-se dentro dos níveis necessários e com valores característicos de uma superfície com boa drenagem superficial e boa oferta de 
atrito. Além disso, pelo método da estéreo fotometria confirmou-se que a mistura do tipo gapgraded apresenta predominantemente textura negativa. Quanto à representatividade da superfície das placas de laboratório e a superfície de pista, as avaliações após certo número de ciclos do simulador de tráfego podem não refletir o que ocorre na pista. Estudos mais aprofundados devem ser realizados para que os estudos de laboratório possam melhor orientar a previsão de comportamento em pista.

Percebe-se queda no número de acidentes logo após a execução da intervenção (junho/julho 2016) no revestimento asfáltico dos Trechos Experimentais, entretanto, para o Trecho Experimental 01 o número de eventos volta a subir no segundo semestre de 2017 enquanto que para o Trecho Experimental 02 se mantém constante, ou seja, a redução passa ser mais eficiente ao longo do tempo.

Em suma, pode-se dizer que os melhores valores de textura do Trecho Experimental 1 explicam a diminuição abrupta de acidentes logo após a intervenção, que não se manteve em decorrência de patologias apresentadas na pista e correções feitas com mistura asfáltica densa. Enquanto que o Trecho Experimental 2 teve uma redução menos expressiva no número de ocorrências, sem subsequente elevação, além de apresentar bons resultados de textura, mas que não se apresentaram como Ótimos.

Esses resultados confirmam que a intervenção no pavimento, pela incorporação de uma mistura do tipo gap-graded, tem resultado positivo na redução de acidentes, apresentando-se como solução para implementação em outras rodovias.

\section{AGRADECIMENTOS}

Os autores agradecem à Escola Politécnica da Universidade de São Paulo, à Coordenação de Aperfeiçoamento de Pessoal de Nível Superior - Brasil (CAPES) - Código de Financiamento 001, à ARTERIS ("Autopista Régis Bittencourt") pelo apoio e disponibilização de informações para o desenvolvimento da pesquisa, e à Agência Nacional de Transportes Terrestres (ANTT) pelo financiamento através do programa de Recursos de Desenvolvimento Tecnológico.

\section{REFERÊNCIAS}

AASHTO (2010) Highway Safety Manual, v.1. American Association of State Highway and Transportation Officials, Washington, D.C.

Aps, M. (2006) Classificação da Aderência Pneu-Pavimento pelo Índice Combinado IFI - International Friction Index para Revestimentos Asfálticos. Tese de Doutorado, Escola Politécnica, Universidade de São Paulo, São Paulo, SP.

ASTM (2015) E1960-07: Standard Practice for Calculating International Friction Index of a Pavement Surface. American Society for Testing and Materials.

ASTM (2018) E1845-15: Standard Test Method for Calculating Pavement Macrotexture Mean Profile Depth. American Society for Testing and Materials.

ASTM (2018) E303-93: Standard Test Method for Measuring Surface Frictional Properties Using the British Pendulum Tester. American Society For Testing And Materials.

ASTM (2018) E965-15: Standard Test Method for Measuring Pavement Macrotexture Using a Volumetric Technique. American Society for Testing and Materials.

Bernucci, L. L. B.; L.M. G. Motta; J. A. P. Ceratti e J. B. Soares (2008) Pavimentação Asfáltica: formação básica para engenheiros. Abeda - Petrobrás, Rio de Janeiro, 2008.

Caliendo, C.; M. Guida e A. Parisi (2007) A crash-prediction model for multilane roads. Accident Analysis and Prevention, n. 39, p. 657-670. DOI:10.1016/j.aap.2006.10.012.

Carlson, P. J.; E. S. Park e C. K. Andersen (2009) Benefits of Pavement Markings. Transportation Research Record: Journal of the Transportation Research Board, n.2107, p.59-68. DOI: 10.3141/2107-06.

Chou, C.; C. Lee; A. Chen e C. Wu (2017) Using a constructive pavement texture index for skid resistance screening. International Journal of Pavement Research and Technology, n.10, p.360-368. DOI:10.1016/j.ijprt.2017.05.002

CNT (2017) Transporte rodoviário: desempenho do setor, infraestrutura e investimentos. Confederação Nacional dos Transportes, Brasília.

Corley-Lay, J. B. e J. N. Mastin (2007) Ultrathin Bonded Wearing Course as Pavement Preservation Treatment for Jointed Concrete Pavements. Transportation Research Record: Journal of the Transportation Research Board, n.2005. DOI: 10.3141/2005-02.

CROW (2009) Road Safety Manual, Record 26, Ede, Holanda. 
DNIT (2006) Manual de Restauração de Pavimentos Asfálticos. Departamento Nacional de Infraestrutura de Transportes, IPR, Rio de Janeiro, RJ.

Flintsch, G. W.; K. K. Mcghee; E. L. Izeppi e S. Najafi (2012) The little book of tire pavement friction. Pavement Surface Properties Consortium.

Freitas, E. e P. Pereira (2008) Análise da qualidade functional e do impacto ambiental de uma Estrada urbana. Anais do 5o Congresso Luso-Moçambicano de Engenharia, Maputo, Moçambique.

Gao, L., M. Liu; Z. Wanga; J. Xie e S. Jia (2019) Correction of texture depth of porous asphalt pavement based on CT scanning technique. Construction and Building Materials, n.200, p.514-520. DOI:10.1016/j.conbuildmat.2018.12.154.

Geedipally, S. R (2005) Analysis of Traffic Accidents Before and After Resurfacing- A Statistical Approach. Department of Science and Technology, Linkopings Universitet, Suécia.

Hall, J. W.; K. L. Smith; L. Titus-Glover; J. C. Wambold; T. J. Yager e Z. Rado (2009) Guide for pavement friction. National Cooperative Highway Research Program - NCHRP Web-Only Document 108, Final Report for NCHRP Project 01-43, Washington, DC.

Hauer, E. (1997) Observational before-after studies in road safety - Estimating the Effect of Highway and Traffic Engineering Measures on Road Safety. Pergamon Press, Oxford, 289p.

Henry, J. J. (2000) Evaluation of pavement friction characteristics. Transportation Research Record: Journal of the Transportation Research Board.

IPEA (2015) Estimativa dos custos dos acidentes de trânsito no Brasil com base na atualização simplificada das pesquisas anteriores do Ipea. Instituto de Pesquisa Econômica Aplicada, Brasília.

Kuchiishi, A. K.; S. C. Callai; T. Vieira e L. L. B. Bernucci (2014) Estudo da macrotextura do pavimento a partir de ensaios de mancha de areia e drenabilidade em conjunto com análise da superfície por estereoscopia. Anais do XXVIII Congresso de Pesquisa e Ensino em Transportes, ANPET, Curitiba, 12p.

Lyon, C.; B. Persaud e D. Merritt (2018) Quantifying the safety effects of pavement friction improvements - results from a large-scale study. International Journal of Pavement Engineering, v. 19, n.2, p.145-152. DOI: 10.1080/10298436.2016.1172709

Noyce, A. D.; H. U. Bahia; J. M. Yambó e G. Kim (2005) Incorporating road safety into pavement management: maximizing asphalt pavement surface friction for road safety improvements - Draft Literature Review and State Surveys. Midwest Regional University Transportation Center, Traffic Operations and Safety (TOPS) Laboratory, Wisconsin.

OMS (2015) Global status report on road safety 2015. Organização Mundial da Saúde, Genebra, Suíça.

Pereira, C. A.; J. B. Soares; I. D. da S. Pontes Filho; V. T. F. C. Branco (2012) Análise da aderência pneu-pavimento em pontos de ocorrência de acidentes. Transportes, v.20, n.2 p.65-74. DOI:10.4237/transportes.v20i2.525.

Vieira, T. (2014) Asphaltic pavement surface analysis and its effects on the tyre-pavement friction performance. Dissertação (Mestrado), Escola Politécnica da Universidade de São Paulo.

Vieira, T. e U. Sandberg (2018) Negative Texture, Positive for the Environment: Results of Horizontal Grinding of Asphalt Pavements. Annals of 97th Transportation Research Board Annual Meeting, Washington, DC.

Wambold, J. C., C. E. J. Antle; J. Henry e Z. Rado (1995) International experiment to compare and harmonize skid resistance and texture measurements. Permanent International Association of Road Congress Report.

Wegman, F. (2016) The future of road safety: A worldwide perspective. International Association of Traffic and Safety Sciences, n.40, p.66-71. DOI:10.1016/j.iatssr.2016.05.003

Woodham, R. J. (1980) Photometric Method for Determining Surface Orientation from Multiple Images. Optical Engineering, v. 19 , n.1, p.139-144. 